\title{
Arte Aparai na Educação Escolar Indígena: o grafismo como recurso visual para o ensino de arte
}

\author{
Aparai Art in Indigenous School Education: the graphics \\ as visual resource for teaching of art
}

\section{Ereu Apalai ${ }^{1}$ Jussara de Pinho Barreiros ${ }^{2}$}

\begin{abstract}
RESUMO: O artigo discute os usos dos grafismos em cestos, como expressão cultural da arte produzida pelos indígenas Aparai, que moram na aldeia Parapará no Parque Nacional da Montanha do Tumucumaque, localizado no Estado do Pará, Brasil. Realizou-se pesquisa bibliográfica com relação aos aspectos históricos e dados populacionais dos indígenas Aparai. Além disso, observação e técnica de entrevista temática foram os instrumentos de coleta de dados aplicados na Aldeia Parapará, caracterizando a pesquisa qualitativa. Cada grafismo tem significado mítico-estético, de acordo, com a tradição e os tipos de marcas indígenas, que tem padrão gráfico de animais interpretados como seres sobrenaturais pelos indígenas Aparai. Os grafismos desenhados em cestos, têm como mito fundante o Turupere, que é a representação dos desenhos do corpo de um lagarto, sendo o seu domínio as águas, além de outros animais que habitam a floresta Amazônica. As cestarias Aparai são produzidas de tala de arumã, madeiras, sementes, algodão, plumagem e tabocas. A maioria dos objetos artesanais são feitos manualmente para uso doméstico ou para caça e pesca, e, são comercializados nas cidades de Oiapoque, Macapá e Belém. O conhecimento indígena é transmitido de geração em geração pela oralidade na Educação Indígena e precisa ser valorizado no ensino de arte, e, na Educação Escolar Indígena como parte do patrimônio cultural intangível ou imaterial.

Palavras-chave: Ensino de Ciência, Ciência da Linguagem, Cultura Aparai no Ensino, Grafismo em Cesto.
\end{abstract}

ABSTRACT: The paper discusses the uses of graphics in baskets as a cultural expression of the art produced by Aparai natives, who live at Parapará village in the Tumucumaque Mountains National Park, located at State of Pará, Brazil. The bibliographical research conducted on the historical aspects and population data of the Aparai natives. Besides that, observation and thematic interviews were the instruments of data collection applied at Parapará village, characterizing qualitative research. Each graphic has a mythical-aesthetic meaning, according to tradition and types of indigenous marks, which has a graphic pattern of animals, interpreted as supernatural beings by Aparai natives. The graphics designed in baskets have as founding myth the Turupere, which is the representation of the drawings of the body of a lizard, being its domain the waters, besides other animals that inhabit the Amazon forest. The Aparai baskets are produced from splint of arumã, wood, seeds, cotton, plumage and "tabocas." Most craft objects are made manually for domestic use, hunting, and fishing, and, they commercialized in the cities of Oiapoque, Macapá, and Belém. Indigenous knowledge is transmitted from generation to generation through orality in Indigenous Education and needs to be valued in the teaching of art, and in the Indigenous School Education as part of the immaterial or intangible cultural heritage.

Keywords: Teaching of Science, Science of Language, Aparai Culture in Teaching, Graphic in Basket.

\footnotetext{
${ }^{1}$ Graduada em Licenciatura Intercultural Indígena pela Universidade Federal do Amapá, com habilitação em Linguagens e Códigos, professora efetiva do Governo do Estado do Amapá, lotada na Escola Indígena Estadual Amatare e pesquisadora do Núcleo de Pesquisa História da Ciência e Ensino. E-mail: ereu.apalai@hotmail.com

2 Doutoranda em História da Ciência pela Pontifícia Universidade Católica de São Paulo, professora assistente da Universidade Federal do Amapá, Curso de Licenciatura Intercultural Indígena, pesquisadora do Grupo História da Ciência e Ensino: Construindo interfaces e do Núcleo de Pesquisa História da Ciência e Ensino. E-mail: jussaraw-ap@ig.com.br
} 


\section{INTRODUÇÃO}

Com relação as terras ocupadas pelos indígenas Aparai, segundo Velthem e Linke (2010, p.14) "há relatos de que os Aparai viviam na região situada entre o baixo curso dos rios Paru d' Este e Jari, onde se relacionavam com outros povos dessa região, os Apama e os Aracayu". Estes autores afirmam ainda, que ao longo da história, os livros escritos pelos historiadores documentaram mais informações sobre o passado dos Wayana do que dos Aparai.

Conforme IBGE (2011) sabe-se que a população da etnia Aparai ${ }^{3}$, segundo o último censo demográfico era de 402 (quatrocentos e dois). Este grupo étnico é falante da língua Karib e faz parte das etnias pertencentes às outras famílias linguísticas não classificadas em troncos.

Velthem e Linke (2010, p. 15) explicam com relação à ocupação de terras pelos indígenas Wayana e Aparai:

No Brasil e atualmente, os Wayana e Aparai habitam em vinte aldeias instaladas em duas terras indígenas, ambas homologadas em 03 de novembro de 1997, através de decreto presidencial, sendo elas a Terra Indígena Parque Tumucumaque e a Terra Indígena Rio Paru d'Este. Esses territórios são contíguos e estão localizados no norte do estado do Pará, estendendo-se pelos municípios de Oriximiná, Óbidos, Almerim, Alenquer e Monte Alegre, e uma pequena parte do estado do Amapá, no município de Laranjal do Jari.

Alguns indígenas Aparai moram no município de Almeirim no Norte do Pará, próximo ao rio Paru. Ao longo deste rio possui aproximadamente vinte aldeias, sendo a maior, a Aldeia Bona, que é habitada pelos indígenas Aparai. A aldeia Parapará também é habitada por este grupo étnico e outras aldeias.

Apowaiko Apalai Wayana com relação ao isolamento do território ocupado pelos Wayana e Aparai, relata que: "Nós Wayana, Apalai convivemos [entre nós] e somos muito diferentes de outros povos indígenas. Nós moramos mais longe da cidade, transporte somente aéreo para nos levar para a cidade", conforme citado por Velthem e Linke (2010, p. 17).

Sabe-se pela tradição oral que a convivência dos Wayana e Apalai ocorre desde os tempos antigos. "No Brasil, os Aparai e Wayana mantêm, há pelo menos cem anos, relações estreitas de convivência, coabitando as mesmas aldeias e casando entre si". (BARBOSA, 2007, p. 2).

Nesta pesquisa abordamos o estudo dos usos dos grafismos nas cestarias como expressões culturais da arte produzida pelos indígenas Aparai, buscando refletir sobre os grafismos como recurso visual para o ensino de arte na Educação Escolar Indígena.

\footnotetext{
${ }^{3}$ No referido documento a grafia de "aparai" é apresentada como "Apalaí". Mas optamos neste artigo em mencioná-lo como aparai, pois é a maneira mais referendada em fontes impressas.
} 
A presença dos grafismos na confecção das cestarias é marcante como padrões decorativos, que constituem um objeto de representação gráfica da arte Aparai, envolvendo na arte de entrelaçar o tarumã na confecção de cestos, conhecimento indígenas transmitidos de geração em geração entre os Aparai.

Espera-se que o resultado desta pesquisa contribua com a valorização do conhecimento indígena como "patrimônio cultural imaterial" ${ }^{4}$ na Educação Escolar Indígena, em especial, no ensino de arte.

\subsection{Arte Aparai: Da utilização dos grafismos em cestarias}

Na confecção de artefatos ou objetos da arte Aparai são utilizados diferentes tipos de grafismos que representam animais da floresta amazônica e seres sobrenaturais do universo mítico. Cada grafismo tem significado mítico-estético, de acordo com a tradição oral mantida entre os indígenas Aparai. Os grafismos desenhados nas cestarias Aparai têm como mito fundante o Turupere, que é a representação dos desenhos do corpo de um lagarto, onde o seu domínio são as águas, além de outros animais que habitam a floresta Amazônica.

Velthem e Linke (2010) comentam com relação à narrativa de Enemha Apalai Waiana que trata do desenho da onça Ëglainsïmë:

Para explicar a obtenção dos grafismos, a narrativa começa indicando que Tulupere - Turupere habitava em uma serra junto ao igarapé Asiki - Axiki, um afluente do rio Paru de Leste. Segundo os Waiana, o sobrenatural vivia com seres que para ele trabalhavam, uns caçando como uma onça, denominada Ëglainsïmë e outros transportando a caça, como a centopeia Kumepepïmë (VELTHEM; LINKE, 2010, p. 25).

As narrativas míticas descrevem que os grafismos de cestarias surgiram da pele do ser sobrenatural chamado de Turupere. Estas narrativas são transmitidas pelos indígenas mais velhos nas aldeias e aos poucos passaram a ser contadas por alguns professores indígenas.

\footnotetext{
${ }^{4}$ Para definição de patrimônio cultural imaterial, vide: GALLOIS, D. T. Patrimônio cultural Imaterial e Povos Indígenas: Exemplos no Amapá e norte do Pará, p. 10.
} 
Figura 1 - Desenho da onça Ëglainsïmë

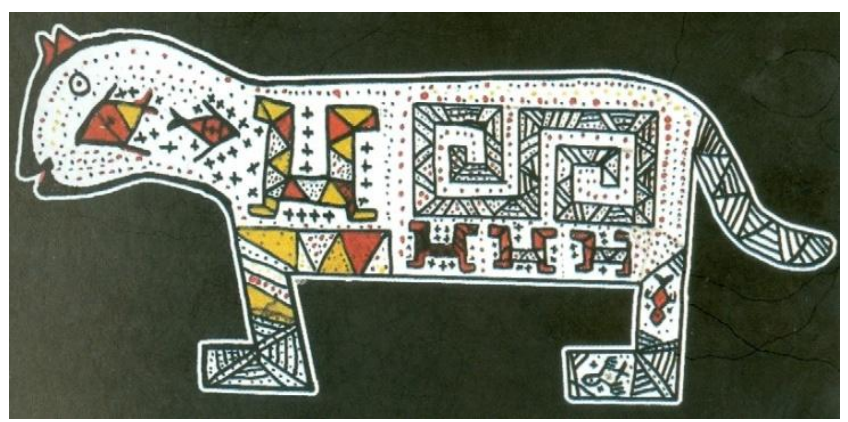

Fonte: VELTHEM; LINKE, 2010, p. 25.

Os Aparai e Waiana produzem artefatos e objetos de diversos tamanhos, com usos de desenhos de animais na forma de grafismos. Estes foram narrados na mitologia antiga pela tradição oral, como o caso do "mito da largata kurupêakê" 5 .

Autores da área da Antropologia e Etnomatemática realizaram pesquisas sobre grafismo indígena ou marcas, arte gráfica, motivos geométricos e ornamentação geométrica, temáticas que envolvem o universo das artes indígenas e a aritmética, em particular, de Povos Indígenas do Norte do Brasil.

Assim, há de se considerar que:

O conhecimento sobre a chamada "arte indígena" é de um modo geral, ainda pequeno. Até mesmo na temática indígena arte é, de uma forma geral, relegada a um plano menos importante. $O$ mesmo se passa no âmbito das artes: privilegiamos o conhecimento plástico sobre os grandes "ismos" da história da arte, e não observamos a riqueza das manifestações plásticas indígenas (CARVALHO, 2003, p. 5).

O autor faz referências aos movimentos artísticos reconhecidos pela história da arte, em seus diversos estilos, o que ele nomeia de conhecimento plástico sobre os grandes "ismos". Com relação às manifestações plásticas indígenas, isto é, as artes indígenas no Brasil, há diferentes interpretações sobre a questão. (BARBERO; STORI, 2010).

Segundo Barbero e Stori (2010), a arte indígena já foi denominada de diferentes formas, como arte primitiva, arte tribal, arte tradicional, arte nativa e arte índia. Na interpretação de Velthem (1992) estas nomenclaturas remetem a julgamento de valores, embasadas numa visão colonialista de que a arte mais evoluída são aquelas das culturas dominantes a partir de considerações de Silver.

A referida autora ainda explica:

Apenas recentemente a pintura, a arte gráfica e os ornamentos do corpo passaram a ser considerados como material visual que exprime a concepção tribal de uma pessoa humana, a categorização social e material e outras mensagens referentes à ordem cósmica. Em resumo, manifestações simbólicas estéticas

${ }^{5}$ VELTHEM, L. H. V. Das cobras e largatas: a iconografia Wayana, p. 53. 
Velthem defende que "como não existe algo chamado "índios do Brasil", não existe também a arte de "nossos índios". Cada povo tem um nome e uma produção específica e os artistas também possuem nomes e uma identidade pessoal definida ${ }^{6}$. Contudo, Vidal discute a temática como dimensão cosmológica em relação aos padrões gráficos, o que também é entendido como grafismo indígena.

Entretanto, as marcas representam uma linguagem simbólica, por meio, dos motivos geométricos. Já na interpretação de Vidal $(2009$, p. 56) "as marcas formam um conjunto expressivo e específico de motivos decorativos, pintados, gravados, traçados, recortados, em diferentes suportes, objetos da vida cotidiana ou cerimonial". Os padrões técnicos e artísticos dessas marcas estão associados ao mundo mítico da cultura indígena.

Por outro lado, a arte gráfica indígena está profundamente enraizada na sua vivência e mitologia. Em virtude disso, as representações iconográficas de identidades étnicas são afirmadas, assim como a produção artesanal para fins outros, que não os da subsistência e as maneiras como vêm sendo utilizados (RIBEIRO, 1986).

Estes se remetem aos sistemas organização social e mitos, bem como aos papéis rituais. Ainda Ribeiro (1986) esclarece que os sistemas representacionais expressam a estrutura formal e semântica dos desenhos e os simbolismos socioculturais, e, que estudam os significados explícitos dos signos plásticos das artes indígenas.

De acordo, com a tradição ancestral, os motivos geométricos e ornamentos geométricos são formas de desenhos que representam o mundo do sobrenatural, como afirma Vidal (2009). Estas marcas são sempre motivos geométricos, abstratos e nomeados, que representam ícones, espécimes da flora e da fauna, especialmente a pele, as escamas ou o casco de animais e cascas de árvores que apresentem desenhos, mas também caminhos, rastros e outras representações são feitas.

Com relação ao modo de vida dos indígenas Wayana e Aparai sabe-se que:

Os Wayana e Aparai possuem um jeito próprio de viver que constitui um imenso legado de experiências, de saberes e de conhecimentos únicos, compartiIhados apenas entre os membros dessas sociedades e que não se confundem com os modos de viver de outros povos indígenas no Brasil (VELTHEM; LINKE, 2010, p. 17).

A visualidade gráfica expressada nos artefatos, por meio, dos grafismos Wayana e Aparai representam um universo simbólico de seres sobrenaturais que transcendem as relações entre humanos. Esta admite diversos seres e forças da natureza, com os quais estabelecem relações de cooperação e intercâmbio, com fim de adquirir e assegurar determinadas qualidades gráficas, de uma tradição milenar de épocas e identidades

\footnotetext{
${ }^{6}$ VIDAL, L. B. Grafismo Indígena: estudos de antropologia estética, p. 290.
} 
étnicas diferentes.

Para exemplificar, a visualidade gráfica, referendamos o trabalho de Gerdes (2002). Ele analisou os motivos de ornamentação geométrica de cestos produzidos por indígenas do Norte do Brasil, abordando sobre a aritmética na ornamentação de cestos cilíndricos de fundo circular e quadrado, que são feitos a partir dos entrelaçamentos de tiras do material usado pelos indígenas.

Figura 2 - Cestos A, B, C e D da esquerda para direita, com base superior de formato circular

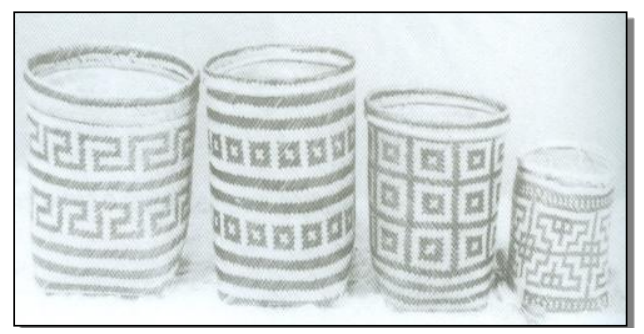

Fonte: GERDES, 2002, p.206.
Figura 3 - Cestos A, B, C e D da esquerda para direita, com base inferior de formato de quadrado

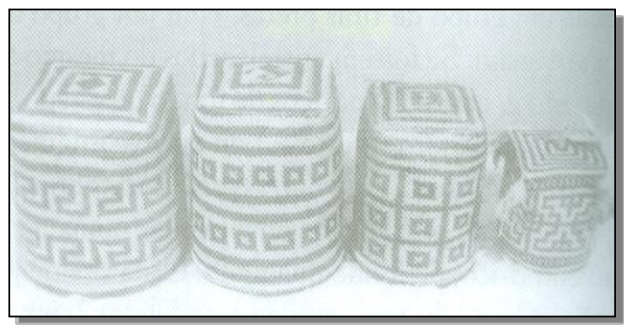

Fonte: GERDES, 2002, p. 208.

Neste estudo evidenciou-se que os padrões geométricos para entrelaçamento do cesto envolvem um disseminado número de tiras da planta utilizada como matéria prima. Para que a ornamentação dos cestos apresente uma simetria rotacional, é preciso que se tenha uma simetria com valor estético, onde o artesão no seu processo de confecção dos cestos escolhe um número de tiras, de tal modo que haja, em cada nível horizontal dos cestos, espaços necessários e suficientes para que o mesmo elemento do padrão geométrico apareça repetidamente (GERDES, 2002).

Gerdes (2002, p. 219) explica que os "inventores dos motivos de ornamentação geométrica analisados tinham conhecimento exato das interconexões geométricoaritméticas entre os padrões do fundo quadrado e da parede cilíndrica dos cestos".

Já Andrade (2009) ao divulgar a cultura indígena ${ }^{7}$ no livro Turé dos Povos Indígenas do Oiapoque, o autor aborda temas como o turé, os karuãna, o pajé e seus ajudantes, bem como sobre os cantos, os artefatos, os mastros, as regras, o caxixi, as marcas e os enfeites dos corpos. Assim, ele trata de vários tipos de artefatos das culturas Paliku, Galibi Kali'na, Galibi-Marworno e Karipuna, cujas confeç̧ões observamos a presença das marcas indígenas.

As marcas indígenas são interpretadas também como grafismos. Para Velthem e Linke (2010), os grafismos que são empregados pelos Wayana e pelos Aparai constituem uma arte que é representacional, descritiva e que se expressa visualmente através das linhas dos desenhos. Por outro lado, os grafismos são formas de expressões artísticas, relacionadas com a tradição oral.

${ }^{7}$ Ref. aos indígenas Paliku, Galibi Kali'na, Galibi-Marworno e Karipuna. 


\section{METODOLOGIA}

Inicialmente realizamos uma pesquisa bibliográfica, com relação a alguns aspectos da arte indígena no Brasil. Segundo Santos, Molina e Dias (2007) a pesquisa bibliográfica é um tipo de pesquisa obrigatória para qualquer trabalho científico, isto é, um estudo organizado com materiais publicados, como livros, periódicos e outros materiais que são fontes de informação e de conhecimento.

Em seguida, realizamos uma pesquisa qualitativa, pois em obras impressas o objeto do estudo desta pesquisa não é abordado de forma explícita. Teixeira (2003, p. 127) explica que na pesquisa qualitativa, "o pesquisador procura reduzir a distância entre a teoria e os dados, entre o contexto e a ação, usando a lógica da análise fenomenológica, isto é, da compreensão dos fenômenos pela sua descrição e interpretação".

Para coletar os dados sobre a arte Aparai no ensino de arte na Educação Escolar Indígena realizamos entrevistas temáticas, em 2013, com Jakeh Apalai (a Cacique), Cecília Awaeko Apalai (Professora Indígena), Maerapo Apalai (Professor Indígena), Paulo Ronaldo Apalai (Professor Indígena), Jaruanare Apalai (Estudante Indígena) e Arinaware Apalai Wayana (Estudante Indígena). Ainda em 2013, Ereu Apalai estava desenvolvendo o Projeto de Pesquisa: Artesanato Aparai: O Uso de grafismos nas cestarias dos povos da Terra Indígena Rio Paru d'Este, no norte do Pará ${ }^{\prime}$, como atividade de pesquisa obrigatória do Curso de Licenciatura Intercultural Indígena da Universidade Federal do Amapá/Campus Binacional de Oiapoque.

As discussões de Meihy e Holanda (2007) serviram de suporte teórico para preparação ao momento de lidarmos com as fontes orais, isto é, suas considerações sobre a seleção dos entrevistados, o local apropriado e da concordância do entrevistado em participar da pesquisa, o tempo previsto adequado das entrevistas, o aparelho tecnológico testado com antecedência para fazer as gravações, a transcrição e a conferência das informações e outros aspectos do uso da história oral na pesquisa.

As etapas envolvidas no processo das entrevistas temáticas foram o planejamento do roteiro de entrevista pelas autoras deste artigo e sua aplicação ocorreu na aldeia Parapará, momento em que Ereu Apalai realizou as entrevistas com os colaboradores desta investigação. Os próprios entrevistados fizeram o registro manual dos dados orais para serem citados no produto da pesquisa. Além disso, realizamos alguns registros fotográficos de artefatos produzidos pelos indígenas Aparai, caracterizando a utilização de "fonte icnográfica" ${ }^{9}$ como recurso visual para complementar as fontes orais e impressas.

\footnotetext{
${ }^{8}$ Linha de pesquisa: Ensino de Ciências, Qualidade de Vida e Cultura Indígena do Núcleo de Pesquisa História da Ciência e Ensino (NUPHCE/UNIFAP/CNPq), orientadora pela Prof. ${ }^{a}$ Ma. Jussara de Pinho Barreiros.

${ }^{9}$ Para a discussão sobre as fontes iconográfica, vide: PEREIRA, S. M. C. Considerações sobre a fonte iconográfica na escrita da História Indígena. Revista Eletrônica História em Reflexão, p. 1-13.
} 


\section{RESULTADO DA PESQUISA QUALITATIVA E DISCUSSÃO}

$\mathrm{Na}$ arte aparai é frequente a presença de diferentes grafismos em artefatos, com objetivo de representar os seres do mundo da natureza e do mundo sobrenatural, como, na confecção de abanos, cestos, sacolas, esteiras, colares, bordunas e outros.

Com relação ao êxito temático a arte de entrelaçar a tala de arumã para fazer os cestos Aparai, Cecília Awaeko Apalai (2013) relatou que:

Os grafismos na confecção dos cestos Aparai são feitos pela habilidade da pessoa que trabalha com a arte das cestarias. O grafismo é sempre padronizado e numerado. Todos os grafismos têm nomes na língua Karib. Nos cestos Aparai, os desenhos dos grafismos representam a onça (kaikuxi), o lagarto (piritumare), a raiz de arumã (aruma mity), o pássaro (touserere), o focinho do caititu (pakira otuhtopõpyry), a flor da sororoca (anaxinekuru), o lagarto (atãta) e outros.

Figura 4 - Cestos grandes com os entrelaçados dos grafismos atãta, irikai, meri e kaikuxi

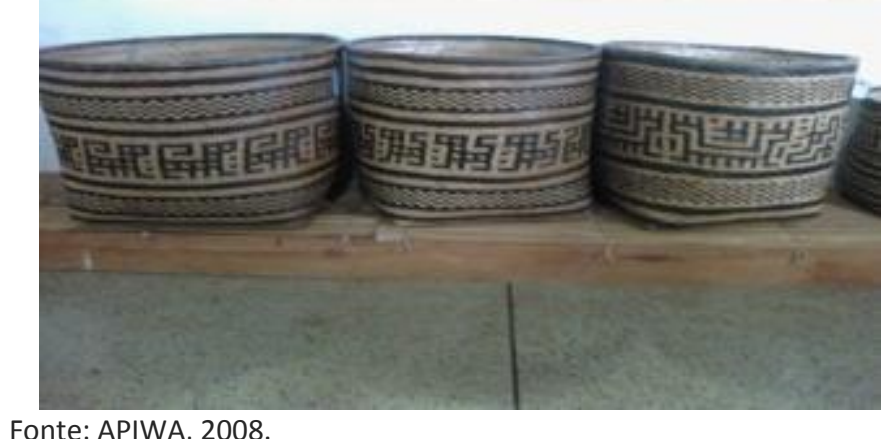

Fonte: APIWA, 2008.

A (Figura 4) mostra três $\operatorname{cestos}^{10}$ que são feitos de tala de arumã, onde observamos quatro tipos de grafismos. No terceiro cesto notamos a representação de lagartos (grafismo atãta) acompanhados de um pequeno peixe (grafismo irikai). Já segundo e primeiro cestos observaram as representações de esquilos (grafismo meri) e onças (grafismo kaikuxi).

Estes cestos são feitos pelos indígenas Aparai a partir dos conhecimentos transmitidos oralmente pelos mais velhos aos aparais mais jovens, como também observando a confecção dos cestos. No planejamento na Educação Escolar Indígena, os professores indígenas ou não indígenas podem incluir o tema sobre a arte de entrelaçar a tala de arumã para fazer os cestos aparai e outros artefatos como um conteúdo específico no ensino de arte.

Quanto a sua experiência de trabalhar a arte aparai na Educação Escolar Indígena, Maerapo Apalai (2013), Cecília Awaeko Apalai (2013) e Paulo Ronaldo Apalai (2013) falaram:

${ }^{10}$ A tradução da palavra "cesto" em língua Karib é "ruto". 
Eu trabalho a arte aparai com os alunos em aulas de arte na educação infantil na escola indígena;

Ensinar a arte indígena no ensino fundamental é importante para que os alunos conheçam os desenhos dos grafismos na arte de entrelaçar a tala do arumã para fazer cestos, abanos, esteiras, maracás, jamaxis, abajus e outros;

É importante ensinar aos alunos para que tenham conhecimentos sobre a arte indígena e também para ensinar os seus filhos no futuro.

A primeira resposta revela que o Maerapo Apalai (2013) desenvolve o conteúdo arte aparai na disciplina de arte em turmas da educação infantil na Educação Escolar Indígena. Assim, o professor indígena trabalha, tendo como suporte teórico a discussão de que o ensino da arte contribui para:

- Compreender a arte como uma forma de expressão e comunicação presente em todos os povos, de diferentes tempos e lugares, reconhecendo a pluralidade cultural como um direito de todos os grupos sociais.

- Compreender a importância da arte como patrimônio e como elemento formador da identidade étnica e cultural.

- Refletir sobre as diferentes linguagens da arte (música, teatro, dança, artes visuais), como se apresentam em sua cultura e em outras, estudando a sua história, identificando e experimentando técnicas, materiais e recursos, procedimentos criativos e de apreciação.

- Ampliar a imaginação, a percepção, a reflexão, a intuição, a fantasia, a observação, a sensibilidade e demais potencialidades necessárias à produção e apreciação da arte, bem como à construção de outros conhecimentos.

- Valorizar as diferentes expressões artísticas de sua sociedade e o conhecimento de seus produtores.

- Identificar aspectos que singularizam a arte de sua cultura frente a outras culturas, indígenas ou não.

- Reconhecer a importância de registrar, conservar e divulgar as produções artísticas de sua sociedade e de outras, sabendo organizar informações e utilizar recursos, materiais, técnicas e procedimentos variados. (BRASIL, 1998, p. 196).

Já Cecília Awaeko Apalai (2013) e Paulo Ronaldo Apalai (2013) destacaram que o ensino da arte aparai é importante em curso do ensino fundamental na Educação Escolar Indígena, como uma forma de se conhecer a arte indígena. Um exemplo de um conteúdo da disciplina de arte pode ser os usos dos grafismos na arte de entrelaçar a tala do arumã para confeccionar vários artefatos e objetos.

Este assunto pode ser discutido em sala de aula, como temas relacionados com: a- Arte, expressão e conhecimento, b- Arte e pluralidade cultural, c- Arte, patrimônio e identidade, conforme proposto no Referencial Curricular Nacional para Escola Indígena. (BRASIL, 1998, p. 296).

Na (Figura 5) observamos um abano aparai que é um objeto utilitário. Na maioria das vezes, ele é confeccionado pelos indígenas Aparai, tendo como matéria prima (talas de arumãs, varas do mato, flechas e linhas feitas de recursos naturais). Geralmen- 
te, este artefato é usado pelas mulheres Aparai para abanar o fogo durante a produção da farinha de mandioca, como também para virar e retirar o beiju do forno. No centro deste abano aparai notamos a representação de dois esquilos que estão se olhando ao mesmo tempo (grafismo de meri).

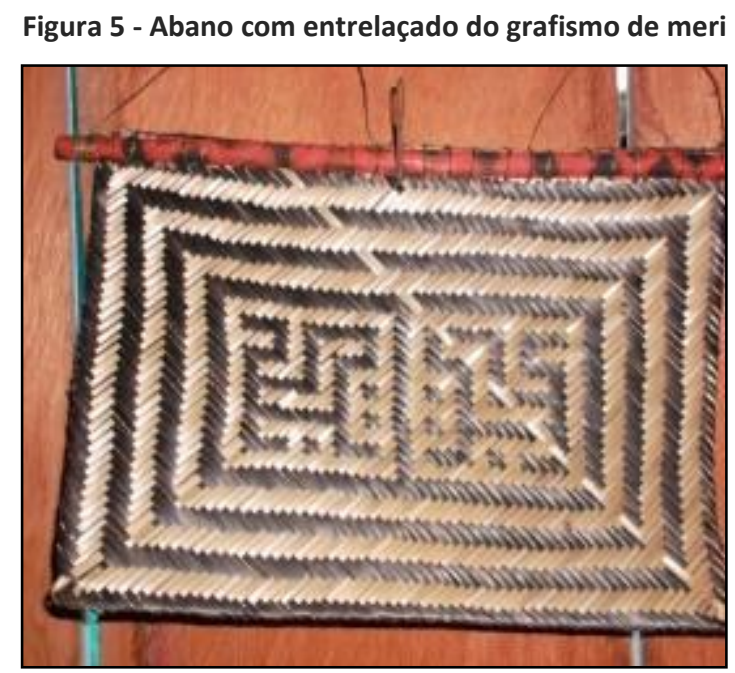

Fonte: APALAI, 2011.

Já a (Figura 6) mostra que com o entrelaçado da tala de arumã para confeccionar um cesto pequeno, se fez a representação do focinho de caititu (grafismo pakira ekuhtopõpyry) a partir conhecimentos da mitologia dos indígenas Aparai mais velhos, pois são eles que conhecem as técnicas da arte de entrelaçar a tala de tarumã para produzir artefatos.

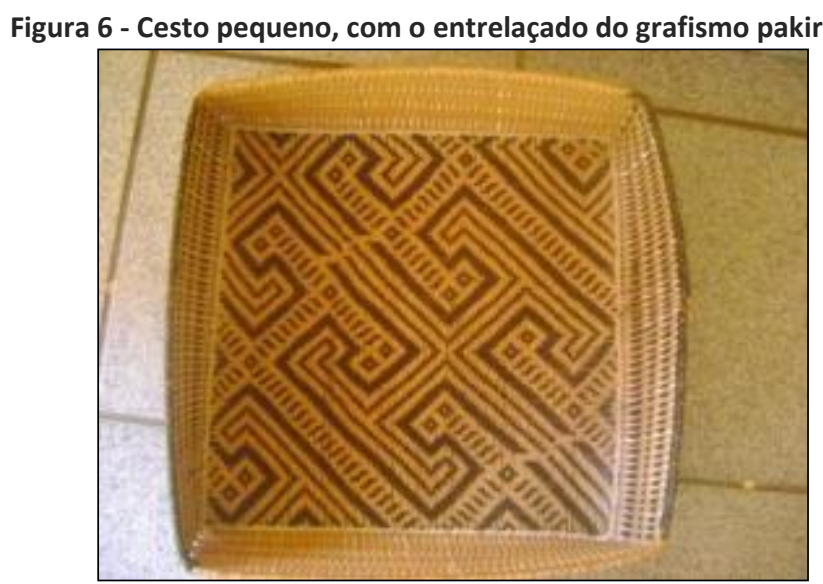

Fonte: APIWA, 2008.

Jaruanare Apalai (2013) esclareceu sobre a arte de entrelaçar a tala de arumã para fazer os cestos aparai na aldeia Parapará e o significado das representações em cestarias, quando concedeu a sua entrevista: 
Para mim, a representação de cestaria significa que eu posso me identificar como indígena, para que não esqueça a minha cultura e história mitológica. Todos os grafismos têm suas próprias histórias de acordo com a mitologia dos antigos.

Este trecho da entrevista explica que as cestarias expressam as diferentes representações e significados dos grafismos traçados nos cestos Aparai. O termo "cestaria" designa o conjunto de objetos, como cestos-recipientes, cestos-coadores, cestoscargueiros, armadilhas de pesca e outros obtidos pelo trançado de elementos vegetais flexíveis ou semi-rígidos (RIBEIRO, 1994).

Com relação à inserção da "Arte Aparai na Educação Escolar Indígena" na educação básica, Arinaware Apalai Wayana (2013) ponderou que:

Para Apalai é muito importante os grafismos nas cestarias para não esquecer a minha cultura e para não esquecer como fazer os cestos. Eu quero que meu fiIho no futuro não se esqueça de que eu repassei para ele, o conhecimento indígena.

No trecho desta entrevista destacou-se a relevância do uso dos desenhos dos grafismos para a cultura Aparai, pois o conhecimento indígena precisa se fazer presente no sistema educacional às gerações de hoje e do futuro na Educação Escolar Indígena.

O poder legislativo normatiza as leis, resoluções e decretos para oferta educação básica no sistema de ensino no Brasil. Assim, é preciso considerar que a Lei no 11.648/2008 tornou obrigatório a inclusão da temática da cultura indígena, afrobrasileira e africana na Educação Básica, bem como a Resolução no 5/2012 que definiu as diretrizes curriculares nacionais à educação escolar indígena na Educação Básica. (BRASIL, 2008, 2012).

Assim, é necessário que se cumpram as legislações e seus desdobramentos com relação ao ensino de arte na Educação Escolar Indígena, tanto pelos motivos declarados por Arinaware Apalai Wayana, moradora da aldeia Parapará/Terra Indígena Paru Rio d'Leste acerca do ensino da arte aparai na educação escolar indígena no norte do Brasil, como também em cumprimento a legislação específica que trata desta temática.

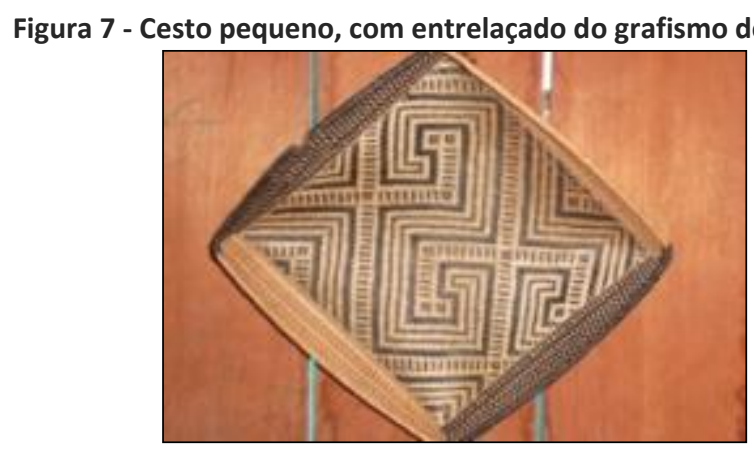

Fonte: APALAI, 2011. 
Já na (Figura 7) ilustra um cesto pequeno (poty) que é feito de tala de arumã com uso de grafismo do toserere, onde se fez a representação de um pássaro. Ele é confeccionado pelos indígenas Wayana e Aparai, expressando um tipo específico de grafismo em um artefato das culturas dos Povos Indígenas do Norte do Brasil.

Por fim, a (Figura 8) mostra uma sacola pequena (sakora) que também é produzida, tendo como matéria prima, a tala de arumã, com uso do grafismo piritumare. Este grafismo representa uma largata sobrenatural que se relaciona com as narrativas míticas do Turupere.

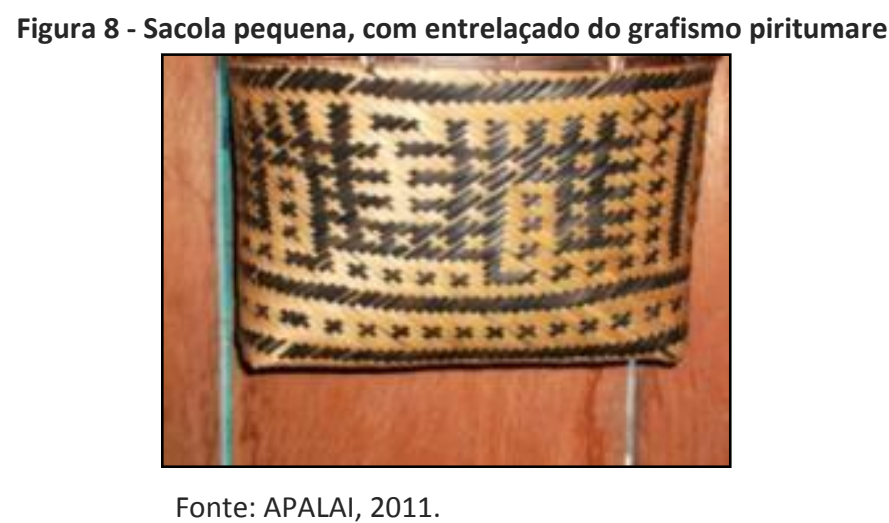

Ela serve para as mulheres Aparai carregarem frutas, sementes, moqueados e guardar algodão, mandioca e outros materiais ou objetos. Já para os indígenas Aparai, esta sacola pequena é usada para guardar os materiais de caça e pesca.

A cacique da aldeia Parapará também participou como entrevistada deste estudo. Ela contribui com a discussão sobre como aprendeu a fazer os cestos e o que pensa a respeito da valorização da arte aparai.

A este respeito, Jakeh Apalai (2013) explicou que:

Antigamente nossa aprendizagem era observando os mais velhos trançando as cestarias, a gente tinha interesse em aprender, pois os antigos contavam a história da mitologia "Turupere", o sobrenatural e o que representam os grafismos.

São vários os tipos de grafismos e suas formas são representadas na confecção de cestos de acordo com mitologia indígena, pois há muito tempo os indígenas Aparai acreditam ter matado o "Turupere", isto é, o lagarto na boca do igarapé Axiki. Este é o lugar em os antigos indígenas viram os desenhos da pele da cobra e depois passaram a reproduzi-los em seus artefatos em gerais.

A técnica da arte de traçar a tala de arumã é praticada somente pelos indígenas Aparai para confeccionar os cestos. Os mais velhos dominam a técnica em suas memórias e repassam esses conhecimentos indígenas, fazendo demonstrações para os jovens Aparai que têm interesse em aprender a referida técnica. A maioria dos Aparai do sexo masculino sabem fazer os cestos, o que faz parte da expressão artística da cultura Apa- 
rai.

Para os indígenas Aparai, o uso do grafismo é bastante valorizado, pois se relaciona com a mitologia dos Povos Indígenas do Amapá e Norte do Pará. Assim, significa a herança cultural deixada pelos seus ancestrais. Como também a representação dos desenhos dos grafismos são formas de identificar a arte Aparai entre outras manifestações das artes indígenas.

\section{CONSIDERAÇÕES FINAIS}

O tema arte Aparai na Educação Escolar Indígena é importante para pensarmos e refletirmos sobre a diversidade cultural no processos de ensinar e aprender em cada escola indígena do sistema público de ensino. Pois os grafismos podem ser usados como recursos visuais para o ensino de arte na educação básica, como os grafismos atãta, irikai, meri, kaikuxi, pakira ekuhtopõpyry, piritumare e muitos outros.

Os grafismos atãta, irikai, meri, kaikuxi, pakira ekuhtopõpyry e piritumare são bastante usados pelos indígenas Aparai para confeccionar cestos, sacolas e abanos através das técnicas da arte de entrelaçar a tala do arumã, representando o atãta, irikai, meri, kaikuxi, pakira ekuhtopõpyry e piritumare. Por outro lado, os desenhos dos grafismos são expressões artísticas dos indígenas Aparai que revelam uma parte das suas crenças com relação aos mitos e sua relação com os seres do mundo da natureza e do mundo sobrenatural, tendo técnicas específicas e padrões numéricos na arte de entrelaçar a tala do arumã.

Neste estudo não nos detivemos em estudar as referidas técnicas, mas iniciar uma discussão com os professores indígenas, a cacique e os representantes de estudantes indígenas sobre a inserção da arte aparai no ensino de arte em cursos de ensino fundamental e médio na Educação Escolar Indígena.

Para o corpo discente da Escola Indígena Estadual Amataré é essencial estudar a arte Aparai como parte dos conteúdos do ensino de arte, com fim de valorizar a arte de entrelaçar a tala do arumã para confeccionar artefatos sejam eles objetos utilitários, decorativos ou para fim comercial. Mas também porque os grafismos fazem parte da cultura Aparai, da memória dos ancestrais, nos quais os grafismos nos cestos representam a cultura Aparai, ou, pelo fato de ser produzida em escala para a venda nas capitais do país, dando dinâmica à economia das famílias Aparai na aldeia Pararará.

A memória coletiva de cada comunidade indígena, por meio, do resgate da confecção dos artefatos indígenas em que se representam os grafismos são produzidos há muito tempo. Os indígenas Aparai expressam suas habilidades e conhecimentos no ato de confeccionar os cestos através de expressões artísticas e cálculos mentais envolvidos no seu processo.

Ensinar e aprender a arte aparai na Educação Escolar Indígena é uma forma de valorizar a cultura indígena. Mas principalmente de mostrar aos jovens Aparai e demais jovens que na produção das cestarias se desenvolvem a técnica da arte de traçar a tala 
de arumã, mesclada a uma tradição que coloca os grafismos e os padrões numéricos como elementos constituintes da cultura Aparai.

\section{REFERÊNCIAS}

ANDRADE, U. G. (Org.). Turé dos Povos Indígenas do Oiapoque. Rio de Janeiro, São Paulo: Museu do Índio/lepé, 2009.

APALAI, C. A. Entrevista concedida à Ereu Apalai. Aldeia Parapará, 2013.

APALAI, J. Entrevista concedida à Ereu Apalai. Aldeia Parapará, 2013.

APALAI, J. Entrevista concedida à Ereu Apalai. Aldeia Parapará, 2013.

APALAI, M. Entrevista concedida à Ereu Apalai. Aldeia Parapará, 2013.

APALAI, P. R. Entrevista concedida à Ereu Apalai. Aldeia Parapará, 2013.

APALAI, E. Fotografia de abano, com entrelaçado grafismo meri. Aldeia Parapará, 2011.

APALAI, E. Fotografia de cesto pequeno, com entrelaçado do grafismo de toserere. Aldeia Parapará, 2011.

APALAI, E. Fotografia de sacola pequena, com entrelaçado do grafismo piritumare. Aldeia Parapará, 2011.

APALAI, E. Artesanato Aparai: O Uso de grafismos nas cestarias dos povos da Terra Indígena Rio Paru d’Este, no norte do Pará. (Monografia da Licenciatura Intercultural Indígena). Universidade Federal do Amapá. Oiapoque, 2014.

APIWA. Fotografia de cesto com o entrelaçado dos grafismos atãta, irikai, meri e kaikuxi. Macapá, 2008.

APIWA. Fotografia de cesto pequeno com o entrelaçado do grafismo pakira ekuhtopõpyry. Macapá, 2008.

BARBERO, E. P. B.; STORI, N. Artes Indígenas: Diversidade e relações com a história da arte brasileira. Rev. Cient./FAP, Curitiba, v. 5, n. 5, p. 111-124, Jan./Jun., 2010.

BARBOSA, G. C. Os Aparai e Waiana e suas Redes de Intercâmbio. (Tese de (Doutorado em Antropologia Social). Universidade de São Paulo. São Paulo, 2007. Disponível em: http://www.teses.usp.br/teses/disponiveis/8/8134/tde-27112009-104126/pt-br.php, Acesso: 20/08/2017.

BRASIL. Referencial Nacional Curricular para Escola Indígena. Brasília: MEC/SEF, 1998.

. Lei no $\mathbf{1 1 . 6 4 5}$ de 10 março de 2008. Altera a Lei no 9.394, de 20 de dezembro de 1996, modificada pela Lei no 10.639, de 9 de janeiro de 2003, que Estabelece as diretrizes e bases da educação nacional, para incluir no currículo oficial da rede de ensino a obrigatoriedade da temática "História e Cultura AfroBrasileira e Indígena". Disponível em: http://www.planalto.gov.br/ccivil 03/ ato2007-2010/2008/lei//1164 
5.htm, Acesso: 20/08/2017.

. Resolução CNE/CEB № 5 de 22 de junho de 2012. Define Diretrizes Curriculares Nacionais para a Educação Escolar Indígena na Educação Básica. Disponível em: http://mobile.cnte.org.br:8080/legislacao-externo/rest/lei/86/pdf, Acesso: 20/08/2017.

CARVALHO, R. A. P. Grafismo Indígena: Compreendendo a representação abstrata na pintura corporal Asurini. (Monografia em Desenho Industrial - Comunicação Visual.). Pontifícia Universidade Católica do Rio de Janeiro. Rio de Janeiro, 2003. Disponível em: http://www.ricardoartur.com.br/Grafismolndigena.pdf, Acesso: 20/08/2017.

GALLOIS, D. T. (Org.). Patrimônio Cultural Imaterial e Povos Indígenas: Exemplos do Amapá e norte do Pará. São Paulo: lepé, 2011.

GERDES, P. Aritmética e ornamentação geométrica: a análise de alguns cestos de índios no Brasil. In: FERREIRA, M. K. L. (Org.). Idéias matemáticas de povos culturalmente distintos. São Paulo: Global, 2002. p. 206-220.

MEIHY, J. C. S. B; HOLANDA, F. História Oral: Como Fazer, Como Pensar. São Paulo: Contexto, 2007.

PEREIRA, S. M. C. Considerações sobre a fonte iconográfica na escrita da História Indígena. Revista Eletrônica História em Reflexão, Dourados, v. 1, n. 2, p. 1-13, Jul./Dez., 2007.

RIBEIRO, B. G. As artes da vida do indígena brasileiro. In: GRUPIONI, L. D. B. (Org.). Índios no Brasil. Brasília: Ministério da Educação e do Desporto, 1994. p.135-144.

RIBEIRO, B. G. (Coord.). Suma etnológica brasileira. Rio de Janeiro: FINEP, 1986. (Handbook of South American Indians, v. 3).

SANTOS, G. R. C. M.; MOLINA, N. L.; DIAS, V. F. Orientações e dicas práticas para trabaIhos acadêmicos. Curitiba: IBPEX, 2007.

TEIXEIRA, E. As Três Metodologias: Acadêmica, da Ciência e da Pesquisa. $6^{\underline{a}}$ ed. Belém: Unama, 2003.

VELTHEM, L. H. VAN.; LINKE, I. L. V. V. (Org.). Livro da Arte Gráfica Wayana e Aparai: Waiana anon imelikut pampila - Aparai zonony imenuru papeh. Rio de Janeiro: Museu do Índio/FUNAI-IEPÉ, 2010.

VELTHEM, L. H. VAN. Das cobras e largatas: a iconografia Wayana. In: VIDAL, L. (Org.). Grafismo Indígena: Estudos de antropologia estética. São Paulo: Studio Nobel/FAPESP, 1992.

VIDAL, L. B. (Org.). Grafismo Indígena: estudos de antropologia estética. São Paulo: Studio Nobel/FAPESP, 1992.

. Povos Indígenas do Baixo Oiapoque: o encontro das águas, o encruzo dos sa- 
beres e a arte de viver. $2^{a}$ ed. Rio de Janeiro: Museu do Índio e lepé, 2009.

WAYANA, A. A. Entrevista concedida à Ereu Apalai. Aldeia Parapará, 2013.

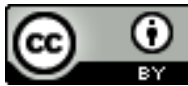

License information: This is an open-access article distributed under the terms of the Creative Commons Attribution License, which permits unrestricted use, distribution, and reproduction in any medium, provided the original work is properly cited.

Article received on May 21, 2017.

Accepted on January 20, 2018. 